\title{
Integrating multidisciplinary design in an undergraduate curriculum
}

\author{
Russell M. Cummings \\ California Polytechnic State Univ., San Luis Obispo \\ H. J. A. Freeman \\ California Polytechnic State Univ., San Luis Obispo
}

\begin{abstract}
AIAA, NASA, and ISSMO, Symposium on Multidisciplinary Analysis and Optimization, 6th, Bellevue, WA, Sept. 4-6, 1996, Technical Papers. Pt. 1 (A96-38701 10-31), Reston, VA, American Institute of Aeronautics and Astronautics, 1996, p. 807-812
\end{abstract}

\begin{abstract}
Multidisciplinary design and analysis (MDA) has become the normal mode of operation within most aerospace engineering companies over the past decade, but universities have not changed their education of engineering students to follow this trend in industry. Under the auspices of NASA, a multidisciplinary team of faculty, student, and industry partners evaluated the aeronautical engineering curriculum at California Polytechnic and found a variety of ways the curriculum could introduce MDA themes without adding courses or units to the existing curriculum. Both analytic and educational tools for MDA have been developed and are in the process of being implemented. (Author)
\end{abstract}




\title{
Integrating Multidisciplinary Design in an Undergraduate Curriculum
}

\author{
Russell M. Cummings * and H. Jo Anne Freeman $\dagger$ \\ California Polytechnic State University \\ San Luis Obispo, CA 93407
}

\begin{abstract}
Multidisciplinary design and analysis (MDA) has become the normal mode of operation within most aerospace engineering companies over the past decade, but universities have not changed their education of engineering students to follow this trend in industry. Under the auspices of NASA, a multidisciplinary team of faculty, student, and industry partners evaluated the aeronautical engineering curriculum at $\mathrm{Cal}$ Poly and found a variety of ways the curriculum could introduce MDA themes without adding courses or units to the existing curriculum. Both analytic and educational tools for MDA have been developed and are in the process of being implemented.
\end{abstract}

\section{Introduction}

Industry wants graduates who are educated as aeronautical systems engineers, with an understanding of the following concepts: how an aircraft should be designed, how an aircraft should be built, and how the two relate to each other. ${ }^{1}$ This project brings together two Cal Poly engineering departments - Aeronautical and Industrial \& Manufacturing - to develop a systematic curricular approach to the integration of manufacturing with the commercial aircraft design process. The specific objective includes creating a curriculum which leads to an overall improvement in design methodology and which meets the needs of industry. Both departments have strong industry support for their instructional and research programs. The faculty have teamed with industry and students to modify the curriculum for this improved educational delivery system. The project includes introducing students to various aspects of multidisciplinary design and analysis (MDA), including the concepts of: design for manufacturing; concurrent

\footnotetext{
* Professor, Aeronautical Engineering Department. Associate Fellow, AIAA.

$\dagger$ Professor and Chairman, Industrial \& Manufacturing Engineering Department.
}

Copyright (C) 1996 by Russell M. Cummings and H. Jo Anne Freeman. Published by the American Institute of Aeronautics and Astronautics, Inc. with permission. engineering; quality and reliability engineering; cost, economic, and market analysis; and legal, ethical, environmental and other social issues. There is also a focus on curriculum modifications to include regulatory laws, specific analytical tools for costing and designing an aircraft for reliability and manufacturability, and manufacturing-based design. Students have been introduced to solids modeling and manufacturing requirements early in the curriculum to improve their concurrent engineering abilities.

\section{The Previous Design Program}

The Flight Vehicle Design course in the Aeronautical Engineering Department has evolved over the past twenty years from a course where students learned how to construct an airplane to courses where they perform detailed preliminary design of an aircraft, including many of its systems. The design curriculum has grown to encompass both undergraduate and graduate students. This evolution has been greatly enhanced by Cal Poly's participation in the NASA/University Space Research Association Program (USRA), enabling the department to give the students a much more intensive aircraft design experience by allowing the students to work on real-world design problems. Many of the aircraft design problems are industry-generated, with industry engineers actively involved in the department's instructional program via an Industrial Advisory Board. The Industrial Advisory Board is made up of approximately twenty engineers and engineering managers from a cross-section of the aerospace industry. They supply the support, both financial and technical, which makes our design course successful.

The current undergraduate aircraft design curriculum at Cal Poly is a well-integrated, intensive, year-long course, requiring prerequisite knowledge in aerodynamics and aircraft structures as well as concurrent knowledge in gas dynamics, propulsion systems, and stability and control. The course includes introductory information on aircraft sizing, aircraft operations, weight estimation, performance requirements, maneuvering, propulsion systems, environmental systems, and configuration layout. Issues which are marginally addressed in the course include environmental impact, economics, and airline requirements. 
The design work is conducted in an inter-disciplinary fashion, with design groups working as teams throughout the three-quarter sequence. The course culminates in an Industrial Design Review and Critique at the end of the year. The industry design review teams are multidisciplinary and include engineers with expertise in aeronautics, manufacturing, propulsion, maintenance, structures, and control systems. The engineers come from Boeing, Lockheed, Northrop, McDonnell Douglas, Rolls Royce, General Electric, United Airlines, as well as NASA and others. The industry partners also contribute greatly to the cost of implementing the course through generous donations. Students gain valuable insight into the difficulties in designing an aircraft within the constraints of a group project with a deadline. Unfortunately, one of the areas where the students are deficient is in tying their designs into the manufacturing world. The current course only marginally addresses issues such as design for assembly (DFA), design for manufacturing (DFM), economic analysis, design to cost and time constraints, and various other considerations.

\section{The New Design Program}

In examining the literature, and taking a hard look at what we are currently doing in our curriculum, we found that the observations of Robert R. Furgason were very true:

\section{One continual comment, especially from employers, is that our engineering graduates are well prepared in the quantitative aspects of the scientific, mathematical, and engineering components of their education, but they often lack what we might term the 'soft' or 'people' skills; that is, the ability to communicate effectively - write, speak, and listen; the ability to work effectively in teams; an appreciation of the economic, environmental, safety, and social factors present in most settings that often dictate the approach that is used; and a realization of the political environment in which they work- both internal and external. In education, we stress the 'right answer' approach and our graduates do not have a good appreciation that most things we deal with are ambiguous and we seek best answers involving many subjective elements. Our curricula should be modified to incorporate these aspects into the educational process. $^{2}$}

The existing curriculum was examined with an eye toward how it currently addresses multidisciplinary topics. A group of faculty and students then brainstormed a list of factors which affect multidisciplinary design within the curriculum as well as other factors which are not within the curriculum. These factors include: problem identification, the design process, the decision-making environment, process identification, and quality issues. A detailed investigation and discussion about each of these issues resulted, with a great deal of information being generated about the gaps and problems within the current curriculum. The areas that were identified include: synthesis vs. analysis, working in groups, "data" (information) and where to find it, willingness to fail and start over (the iterative process), and the student's desire to specialize. In addition, the group realized that there were a number of technical/educational areas where the students simply were not being prepared by the current curriculum, including concurrent engineering concepts, design tools, group dynamics, total quality management (TQM), and a basic understanding of the competitive nature of the commercial aircraft industry.

After developing the concepts for improving the curriculum and developing analytic tools the program was presented to Phil Barkan of Stanford University, a well known expert on engineering product development. Finally, the program was presented to a group of industrial associates consisting of engineering from Boeing, McDonnell Douglas, Northrop Grumman, and NASA Ames Research Center. These engineers would serve as the points of contact for the project, providing input as to how industry is approaching MDA concepts.

Our industrial associates told us that the following areas were of major concern to their companies at the present time: integrated scheduling for manufacturing, computational modeling of manufacturing systems, understanding trade studies and process design, integrated product development, and the use of advanced tools for the design process. In addition, our industry partners said that engineers graduating from universities today are, in general, unprepared to consider an aircraft as a system or to see the design as requiring a collaborative effort. This collaboration is not limited to the traditional relationship between the aerodynamicist, structural engineer, propulsion engineers, and controls systems analyst, but must include being aware of the customer, manufacturing implications, cost analysis, and the time it takes to design and construct an aircraft.

All of these concerns can be summarized as a need to develop a systematic approach to the integration of manufacturing with the aircraft design process. We have addressed the solutions to these concerns by combining three traditionally separate elements: analysis of the market place and the needs of the customers, traditional design analysis, and the manufacturing process. The initial goal is to produce engineering students who are capable of functioning in a complex industry - students who will have the ability to affect the cost, quality, and cycle time of new aircraft products. This goal is realistic, especially considering the tradition of engineering at $\mathrm{Cal}$ Poly and our close ties with industry. 


\section{Multidisciplinary Design and Analysis Curriculum}

The over-riding restraint on any new approaches to engineering education from a MDA perspective was that the MDA material could not add any units to the existing curriculum. Most universities across the country are currently seeking to find ways to reduce the total number of units required for graduation, and our engineering curriculum was already at the maximum number of units allowed. In addition, the curriculum changes had to provide an integrated approach to MDA from the freshman year through the senior year, with modules taking place throughout the student's academic career. We believed that these restraints were inviolable.

There are three main areas within the curriculum which were modified to better prepare the students for tackling MDA themes:

- The freshman engineering curriculum

- Teaching existing engineering analysis courses from a multidisciplinary perspective

- A graduate course to teach the graduate students about the analytic skills necessary to improve the undergraduate curriculum

Faculty activities have included a team-teaching approach to segments of the curriculum where these issues are relevant. The goal is to integrate the multidisciplinary approach throughout the curriculum, from freshman engineering courses through master's-level design courses. This includes a new freshman engineering design course, a new CAD/CAM modeling course, concurrent engineering and manufacturability concepts in various other courses, and a comprehensive approach to design in the senior design courses. Other collaborative efforts have been sought at strategic points in development of the curriculum to enable quality, cost and economics, and concurrent engineering concepts to be introduced.

The current freshman-level engineering curriculum offers the students a variety of courses which are aimed at giving them skills and capabilities for working as engineers in industry. These courses have included a drafting course, a manufacturing survey, and a hands-on course in manufacturing processes (such as casting, sheet metal, etc.). These courses required a total of 5 quarter units (out of a total curriculum of 210 units). The previous courses that introduced freshmen to design documentation and manufacturing were not integrated and the CAD tools were PC-based. It had already been recognized that these courses should be updated and integrated, beginning with combining the drafting course and the manufacturing processes course.
A pilot course for aeronautical engineering students has been introduced to address some of these concerns; Integrated Design and Fabrication (CAD/FAB), which integrates basic knowledge of CAD with manufacturing topics, leading to a project where the students would be required to design, manufacture, and test a product. This course helps to motivate students and excite them about the curriculum, while giving them self-confidence and insights into some of the real problems which are encountered in aircraft design and manufacture.

The integration of CAD/CAM and manufacturing at the freshman level is proposed to occur next. This integrated foundation course is an excellent means to introduce manufacturability, DFA/DFM, and concurrent engineering. At the same time the change to an industrial solid model-based, integrated CAD/CAM tool will occur. Commercial engineering software is installed on SUN workstations at the university and experience in this year's pilot courses shows that solid modeling is easier to teach than wire-frame modeling because of the ease of developing multi-part assemblies, generation of computer-aided engineering (CAE) meshes, drawings, and CAM models. Students will gain a greater degree of understanding through such an integrated course which demonstrates the strong relationship of design decisions to manufacturability.

The Industrial \& Manufacturing Engingeering Department has also developed and implemented three Product-Process Design course for graduate students and seniors within the new Manufacturing Engineering B.S. program. These courses present concurrent engineering concepts, Quality Function Deployment (QFD), ${ }^{4}$ and Design for Manufacturing, Assembly, Maintainability $(\mathrm{DFX})^{5}$ for integrated product engineering. The experience gained in teaching these courses has helped the faculty make important strides in formulating and improving the proposed freshman class for Aeronautical Engineering students.

Changes have also been made in the freshman course which is currently taught in the Aeronautical Engineering Department, Introduction to Aerospace Engineering. This course gives students basic information about airfoils, wings, airplanes, and performance, as well as information about the aerospace industry. The students formerly completed this course by participating in a group balsa wood glider design. ${ }^{3}$ The course has been modified to include a variety of team design projects, including a team rocket design which culminates in a test firing. Students are also introduced to a variety of fundamental MDA concepts, such as the importance of cost and manufacturability to the design process.

The sophomore level computing course, Aerospace Engineering Analysis $I$, is in the process of being modified to include $\mathrm{CAD} / \mathrm{FAB}$, cost analysis, and 
integrated product development. These themes are being introduced within the context of an aircraft performance design problem where the students create a CAD model of an aircraft, evaluate the aerodynamics and performance characteristics using various existing design programs such as ACSYNT, and conclude by manufacturing and reporting on their results. this builds on the student's earlier design experience and extends it to a higher level.

Finally, all existing Aeronautical Engineering courses have being evaluated for inclusion of multi-disciplinary topics, especially for development of the student's understanding of manufacturing and the importance of group projects and teamwork. Team design projects have been added in the junior year in aerodynamics and guidance \& control courses, some of which can be also be merged with existing faculty research and collaboration with industry.

As more "real world" problems are introduced into the curriculum in technical areas such as aerodynamics, controls, structures, and propulsion, the students will see why it is important to think across disciplines, rather than to "compartmentalize" their learning. The end result will be that students are better prepared to conduct multidisciplinary design when they reach the Flight Vehicle Design course in the senior year.

\section{Analytic Tool Development}

A variety of technical areas are lacking within our current curriculum which we believe are necessary to prepare our students to be able to do a better job designing aircraft. These needs fall into a number of categories: aircraft design tools, trade study software, integrated scheduling systems, integrated product development, and various enginecring design and analysis tools. In fact, we were overwhelmed when we looked at the list of technical background requirements for students as they enter an aircraft design course. The problem becomes how to effectively introduce students to a larger body of knowledge without just "throwing" more courses at them. All of this must be done while simultaneously considering that most people believe engineering curricula are already overburdened.

The basic approach is to work on discovering more efficient ways to deliver knowledge to the students, while cnsuring that these technical areas are well covered and thoroughly understood. We have developed computerbased teaching tools which will introduce students to complex topics such as aircraft handling qualities, a topic which is usually beyond the scope of the undergraduate curriculum, but which is a basic requirement for performing a preliminary design. While working with our industrial associates we also determined what is valuable in performing multidisciplinary optimization (robustness, reliability, etc.), systems engineering, and linking various analysis areas. The large quantity of information required for performing multidisciplinary design will have to be shaped into essential analytic areas - each of these areas will have extensive analytic tool development performed by the graduate students.

Examples of some of the engineering design tools which have and are being developed:

Inter-disciplinary optimization: Many of the traditional aircraft design areas such as structures, aerodynamics, propulsion, and controls are often completed semiindependently during the design process. Constraints on one area effect changes in other areas, but rarely are multiple areas designed and optimized simultaneously. A specific example of this is the B-2 wing structure, which ended up being designed for dynamic (aeroelastic) loads rather than strength. This type of inter-disciplinary analysis could be highly beneficial if simplified computational models could be developed for preliminary design.

Designing to meet cost, cost estimating, and learning curves: It is essential for students, as well as industry, to understand cost drivers -- that is, which design decisions lead to costly manufacturing processes? Simple design rules and concepts could be identified and introduced to the students. Although current Industrial \& Manufacturing Engineering courses address these areas, we have not provided adequate preparation to Aeronautical Engineering students in this topic. The project objective was to explore the means by which we can convey these skills to students at an early stage so that they will be able to apply the concepts in their senior design sequence. The project will develop portable teaching/learning modules using computer and multimedia tools.

Integrated Product/Process Development (IPPD): One of the areas which engincering students seem lacking is in their ability to develop and design seeing the "larger picture". A variety of tutorials have been developed which introduce the students to the concepts of IPPD and allow them to realize the impact of this concept on the design process. The tutorials have been implemented on the World Wide Web and can be found listed under NASA AMDAF at http://www.calpoly.edu.

Legal, Social and Ethical Issues: The impact of technology in the human, societal and ethical context is addressed in various elective courses. We believe that these subjects need to be better integrated into the curriculum and not just introduced at a fundamental level. These concepts will be worked into existing project courses such as the freshman introductory course, the senior design course, and group Senior Projects. The proposed project will attempt to develop case study-based learning modules in which the role and context of these 
issues will be conveyed to the students. Faculty from the humanities will be involved in order to give perspective to these issues.

Quality: The engineering strategies to correctly specify and meet quality requirements in design and manufacturing have changed significantly. A course in the Industrial \& Manufacturing Engineering Department, Quality Engineering, includes these emergent approaches. In this project we will develop teaching modules which can be incorporated into junior-level courses for Aeronautical Engineering students in preparation for application of quality engineering in their product design and build activity. We will also explore the applicability of QFD using an aeronautics-oriented case study approach.

Business Aspects, Integration, and Market Analysis: These topics are addressed within the Industrial \& Manufacturing and Business curricula. In this project we will start by assessing the level of need and required level of proficiency for Aeronautical Engineering students. Based on that assessment we plan to develop teaching modules which will provide a structured framework which can be deployed in the aircraft design course sequence. Some structured analysis tools currently in use within Industrial \& Manufacturing Engineering classes will be re-structured for application within the context of aeronautical systems design and implementation.

Approach to team building: Teambuilding is a crucial component of the research and development process. Concurrent engineering has been found to require an increased emphasis on team building, especially because of problems created by the more inter-disciplinary nature of concurrent engineering teams. ${ }^{6}$ It is for this reason, along with our observations of students in their design course and the input we have received from industry, that we believe team building to be a crucial area for the success of multidisciplinary design.

The primary obstacle at the university seems to be the current curriculum style, which promotes independence over teamwork. Students are put through several years of engineering science courses as individuals, where group work is discouraged and even penalized. The problem with this approach has been noted by engincering educators at many universities, and has led to curriculum modifications which introduce group projects in the freshman, ${ }^{7}$ sophomore, ${ }^{8}$ and senior years. ${ }^{9}$ We believe that for the senior design experience to be truly valuable from a team viewpoint, the students must be given team skills earlier in the curriculum and throughout the curriculum.

Team skills of our current students have been observed and tutorials and team-building exercises have been developed. These tools are also being introduced to students in the lower division courses so that their team skills will be well developed by the time they reach the senior design class. A variety of these topics are discussed in greater detail in Refs. 10-13.

\section{Conclusions}

The changes required in order to introduce MDA topics to undergraduate students are large and complex. Existing engineering curriculums are over-burdened and new concepts cannot be introduced by simply adding more courses. A multidisciplinary team approach to solving this problem has resulted in a curriculum modification and analytic tool development program which is well under way at Cal Poly. New approaches to MDA have been added to the curriculum beginning with the freshman year, with planned changes to take place soon in the sophomore and junior years. The Aeronautical Engineering faculty have been very supportive of these changes to the curriculum.

Specific changes to the curriculum include:

- the development of a freshman CAD/FAB course

- modifications of the freshman orientation course to include team design projects

- planned changes to the sophomore programming course to include $\mathrm{CAD} / \mathrm{FAB}$, cost estimating, IPPD, and team work

- various team design projects in the junior year

- new understanding and improvements for the senior design class as a result of the previous curriculum improvements

Specific tools which have been developed:

- IPPD tutorial on the World Wide Web

- teambuilding modules which are currently being put on CD-ROM

- aircraft handling qualities and stability \& control software

In the future we plan to include:

- further integration of the MDA concepts throughout the curriculum

- various inter-disciplinary concepts

- self-paced learning module for cost estimating

These alterations to the curriculum and analytic tool additions have and will make great improvements in the education of Aeronautical Engineering students at $\mathrm{Cal}$ Poly.

\section{Acknowledgments}


This work was sponsored by NASA Training Grant NGT10012, supervised by Gerry Seidel of NASA Headquarters. We also want to thank Phil Barkan of Stanford University for his help in the initial stages of the project. In addition, the engineers of the following organizations have been very important to our work: Boeing, McDonnell Douglas, Northrop Grumman, and NASA Ames Research Center.

\section{References}

1 Nicolai, L.M. "An Industry View of Engineering Design Education" AIAA Paper 93-328, Jan. 1993.

${ }^{2}$ Furgason, R.R. "Update on ABET Accreditation Activities" ABET Memo to Engineering Deans, April 1994.

${ }^{3}$ Biezad, D.J. and R.M. Cummings "Introducing Aircraft Design During the Freshman Year" ASEE Annual Conference Proceedings, 1993, pp. 30-33.

${ }^{4}$ Hauser, J.R. and D. Clausing "The House of Quality" Harvard Business Review, May-June 1988.

${ }^{5}$ Bakerjian, R., Ed. "Design for Manufacturability" SME Tool and Manufacturing Engineers Handbook Series, Vol. VI Dearborn: SME, 1992.

6 Trygg, L. "Concurrent Engineering Practices in Selected Swedish Companies: A Movement or an Activity of the Few?" Journal of Product Innovation Management Vol. 10, 1993, pp. 403-415.

${ }^{7}$ Marchman, J.F. and W.H. Mason "Freshman/Senior Design Education" AIAA Paper 94857, Jan. 1994.

${ }^{8}$ Hollister, W.M., E.F. Crawley, and A.R. Amir "Unified Engineering: A Twenty Year Experiment in Sophomore Aerospace Education at MIT" AIAA Paper 94-851, Jan. 1994.

${ }^{9}$ Johnson, V. and B. Rumbaugh "Educating for Engineering Design Today - Measuring for Excellence Tomorrow: The NASA/USRA University Advanced Design Program" AIAA Paper 94-862, Jan. 1994.
${ }^{10}$ Nowaczyk, R. and D. Levi, "Two Approaches to Teaching Team Skills to Engineering and Science Students," AIAA Paper 96-4068, Sept. 1996.

${ }^{11}$ Kettering, M. and D. Biezad, "The Roadable Aircraft Design Project," AIAA Paper 96-4071, Sept. 1996.

${ }^{12}$ Menon, U., M. Graham, and G. Thompson, "IPPD Tutorial Using The World-Wide-Web: NASA/AMDAF," AIAA Paper 96-4089, Sept. 1996.

${ }^{13}$ Menon, U., M. Graham, and G. Thompson, "Multi-Disciplinary Framework for IPPD in Aeronautical Industry," Proceedings of the Sixth International FAIM Conference, Georgia Tech, May 1996. 